\title{
Mechanistic Insight into Ligand-promoted Palladium-Catalyzed C-H Alkenylation of Simple Arenes with Internal Alkynes: A Computational Study
}

\author{
Weirong $\mathrm{Wu}^{1}$, Hua $\mathrm{Hou}^{1}$, and Yanzhen $\mathrm{Li}^{2}$ \\ ${ }^{1}$ Wuhan University \\ ${ }^{2}$ Chongqing Three Gorges University
}

July 1, 2020

\begin{abstract}
The ligand-promoted palladium-catalyzed hydroarylation of alkynes with arenes without directing group is able to furnish alkenyl chlorides via a 1,4-chlorine migration or trisubstituted alkenes. This reaction is challenging due to bidentate $\mathrm{N}, \mathrm{N}$ ligand and electron-neutral arenes have rarely been reported to afford good yields. We carried out density functional theory calculations to better understand the elementary steps of the reaction and unveil the ligand effects and origin of substituent-controlled chemoselectivity of challenging C-H activation. For the n-propyl-substituted substrate, CMD process is the rate-determining step of the catalytic reaction. And the chemoselectivity is controlled by oxidative addition with the C-Cl bond cleavage and protonation process. However, for the reaction with 3,5-dimethylphenyl-substituented substrate, the key step of the whole catalytic cycle is the protonation process. The stronger electrostatic attractions, repulsive force and aryl substituent effects result in reverse chemoselectivity. Bidentate ligand L1 (2-OH-1,10-phenanthroline) reacts with $\mathrm{Pd}(\mathrm{OAc}) 2$ to form a most stable square-planer species, which is different from the one formed by ligand L2(1,10-phenanthroline). The steric repulsion are found to be mainly responsible for no product with L2 as the ligand, which is different from as proviously reported.
\end{abstract}

\section{Mechanistic Insight into Ligand-promoted Palladium-Catalyzed C-H Alkenylation of Simple Arenes with Internal Alkynes : A Computational Study}

Weirong Wu, ${ }^{*}$ a,b Hua Hou, b Yanzhen Li*a

Abstract The ligand-promoted palladium-catalyzed hydroarylation of alkynes with arenes without directing group is able to furnish alkenyl chlorides via a 1,4-chlorine migration or trisubstituted alkenes. This reaction is challenging due to bidentate N, N ligand and electron-neutral arenes have rarely been reported to afford good yields. We carried out density functional theory calculations to better understand the elementary steps of the reaction and unveil the ligand effects and origin of substituent-controlled chemoselectivity of challenging $\mathrm{C}-\mathrm{H}$ activation. For the n-propyl-substituted substrate, CMD process is the rate-determining step of the catalytic reaction. And the chemoselectivity is controlled by oxidative addition with the C-Cl bond cleavage and protonation process. However, for the reaction with 3,5-dimethylphenyl-substituented substrate, the key step of the whole catalytic cycle is the protonation process. The stronger electrostatic attractions, repulsive force and aryl substituent effects result in reverse chemoselectivity. Bidentate ligand L1 (2-OH-1,10-phenanthroline) reacts with $\mathrm{Pd}(\mathrm{OAc})_{2}$ to form a most stable square-planer species, which is different from the one formed by ligand L2(1,10-phenanthroline). The steric repulsion are found to be mainly responsible for no product with L2 as the ligand, which is different from as proviously reported.

Keywords Ligand-promoted, Alkenylation, Vinyl Chlorides, Chemoselectivity, trisubstituted olefin

\section{Introduction}


Alkynes are widely used in the synthesis of various compounds of practical value, such as non-linear optical materials, liquid crystals, organic semiconductors and sensors. An important synthetic conversion of alkynes is alkenylation reaction with arenes and heteroarenes (Scheme 1), which may be also regarded as a hydro (or other group) -arylation of a acetylene bond ${ }^{1}$. Alkenyl insertion into aromatic and heteroaromatic rings by intermolecular or intramolecular methods provides a reaction route for the synthesis of substituted olefins, for example, styrene, stilbene. ${ }^{2-9}$ Substituted olefins are important intermediates for the preparation of valuable chemicals and have been extensively studied in the past decades. Currently, there are four main synthetic strategies for introducing alkenyl groups into (hetero) aromatic structures using alkynes ${ }^{1}$. Among them, in the first synthesis strategy, various metal-catalyst-catalyzed carbonmetallation of internal alkynes is a direct and effective method for the synthesis of multisubstituted olefins (Scheme 1a). However, these reactions require pre-functionalized metal-organic reagents ${ }^{10}$. In recent years, significant advances have been achieved by transition metal-catalyzed C-H activation for construction complex molecules from simple starting materials. ${ }^{11}$ Directing group (DG)-assisted C-H functionalization strategies have been extensively studied, and various arenes have reacted with alkynes and olefins to form functionalized olefins ${ }^{12}$.

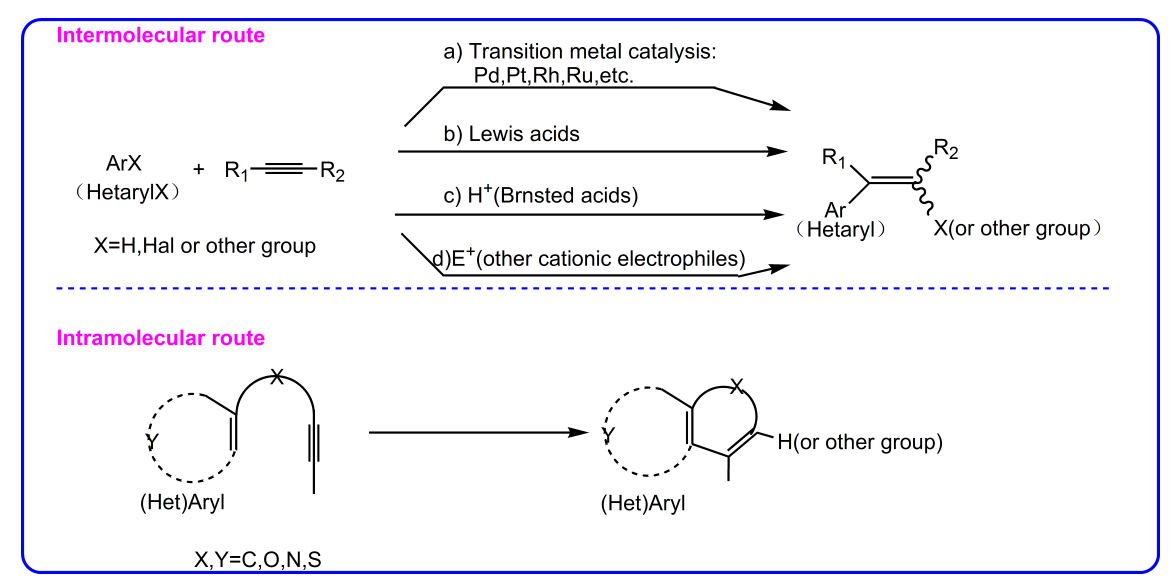

Scheme 1 Main pathways of alkenylation of (hetero)arenes with alkynes ${ }^{1}$.

Ligand-accelerated catalysis, adjusting and controlling the efficiency and selectivity of the catalytic reaction by appropriate ligands, has also been used in $\mathrm{C}-\mathrm{H}$ bond activation ${ }^{13}$.

In contrast, only a few suitable ligands are available for palladium-catalyzed $\mathrm{C}-\mathrm{H}$ functionalization, especially for substrates without chelating groups ${ }^{13 b}$. Generally, $\mathrm{Pd}(\mathrm{OAc})_{2}$ or other simple palladium salts are the widely used catalysts for C-H activation, and the addition of nitrogen ligands inhibit the catalytic activity of palladium catalysts. Recently, Yu et al. ${ }^{14}$ and Sanford et al. ${ }^{15}$ reported that the use of monodentate pyridine ligands increase the activity of palladium catalysts in the $\mathrm{C}-\mathrm{H}$ functionalization of simple arenes. And in this reaction, the coordination of palladium with monodentate nitrogen ligand effectively promotes $\mathrm{C}-\mathrm{H}$ activation reaction $^{16,17}$. However, bidentate nitrogen-nitrogen ligand, 1,10-phenanthroline, is so far rarely used for palladium-catalyzed $\mathrm{C}-\mathrm{H}$ activation, although it is a ligand widely used in catalysis and preparation for various metal complexes ${ }^{18}$. Recently, Duan's group reported for the first time the use of the self-developed bidentate ligand (L1 ), 2-OH-1,10-phenanthroline, to promote the palladium-catalyzed C-H activation of simple arenes with internal alkynes ${ }^{10}$. As shown in Scheme 2 entry 1, the representative reaction protocol between 1,4-dichlorobenzene (1a ) and the n-propyl-substituted alkyne (R1 =n-propyl), $\mathbf{2 a 1}$, employing L1ligand, produces a 82: 9 ratio for a mixture of alkenyl chloride $\left(\mathbf{P}_{\mathbf{R} \mathbf{1}} \mathbf{1}\right)$ and hydroarylation product $\left(\mathbf{P}_{\mathbf{R} \mathbf{1}} \mathbf{2}\right.$ ). In contrast, the ligand was changed toL2 (1,10-phenanthroline), the reaction did not proceed at all and no products were observed (entry 2). In addition, alkenyl chloride $\left(\mathbf{P}_{\mathbf{R} \mathbf{1}} \mathbf{1}\right)$ in $81 \%$ yield was obtained when the substituent of alkyne $\mathbf{2 a}$ was the $\mathbf{R} \mathbf{1}$ group (entry 3 ). However, replacing the n-propyl group in alkyne $\mathbf{2 a 1}$ by the 3,5-dimethylphenyl (R2 ) group (the alkyne substrate is denoted as $\mathbf{2 a 2}$ ) results in a different chemoselectivity: the final hydroarylation product $\left(\mathbf{P}_{\mathbf{R 2}} \mathbf{2}\right)$ with a yield of $91 \%$ (entry 4 ). 


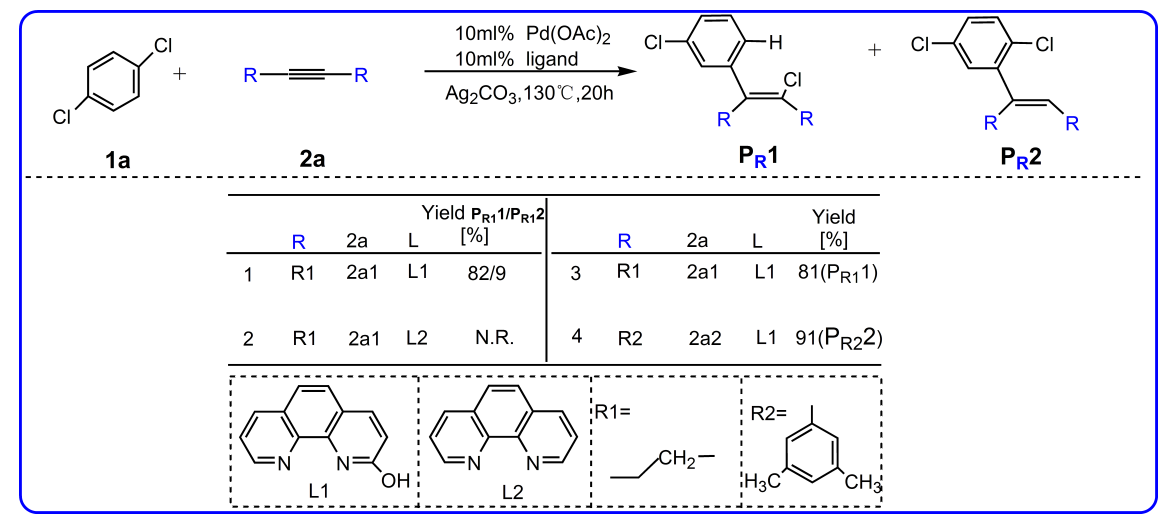

Scheme 2 Palladium-catalysed reaction of 1,4-dichlorobenzene (1a) with internal alkynes (2a) proposed by Duan group ${ }^{10}$.

To elucidate the catalytic reaction, Duan's group performed some mechanistic experiments and proposed possible reaction mechanisms with the substrates dialkylalkyne (2a1 ) and diarylalkyne (2a2 ), respectively. As shown in Scheme 3, L1 ligand reacts with $\mathrm{Pd}(\mathrm{OAc})_{2}$ catalyst to form intermediateA, followed by $\mathrm{C}-\mathrm{H}$ bond cleavage of 1,4-dichlorobenzene, producing arylpalladium B . Alkyne 2a then insertes into the $\mathrm{C}(\operatorname{aryl})-\mathrm{Pd}$ bond to obtain alkenylpalladium intermediateC , from which different reactions occur. For the reaction of $\mathbf{2 a 1}, \mathbf{C}$ undergoes oxidative addition with the $\mathrm{C}-\mathrm{Cl}$ cleavage to form $\mathrm{Pd}$ (IV) species $\mathbf{D}$ via path i. Subsequently, the reductive elimination of $\mathbf{D}$ leads to aryl Pd (II) speciesE , completing the 1, 4-Cl migration. Protonolysis of $\mathbf{E}$ with acetic acid furnishes product $\mathbf{P}_{\mathbf{R} \mathbf{1}} \mathbf{1}$ with the dissociation of the active catalyst $\mathbf{A}$. With respect to the reaction with $\mathbf{2 a 2}, \mathbf{C}$ directly hydrolyzes through path ii, affording product $\mathbf{P}_{\mathbf{R 2}} \mathbf{2}$ without a 1, 4-halide shift. 


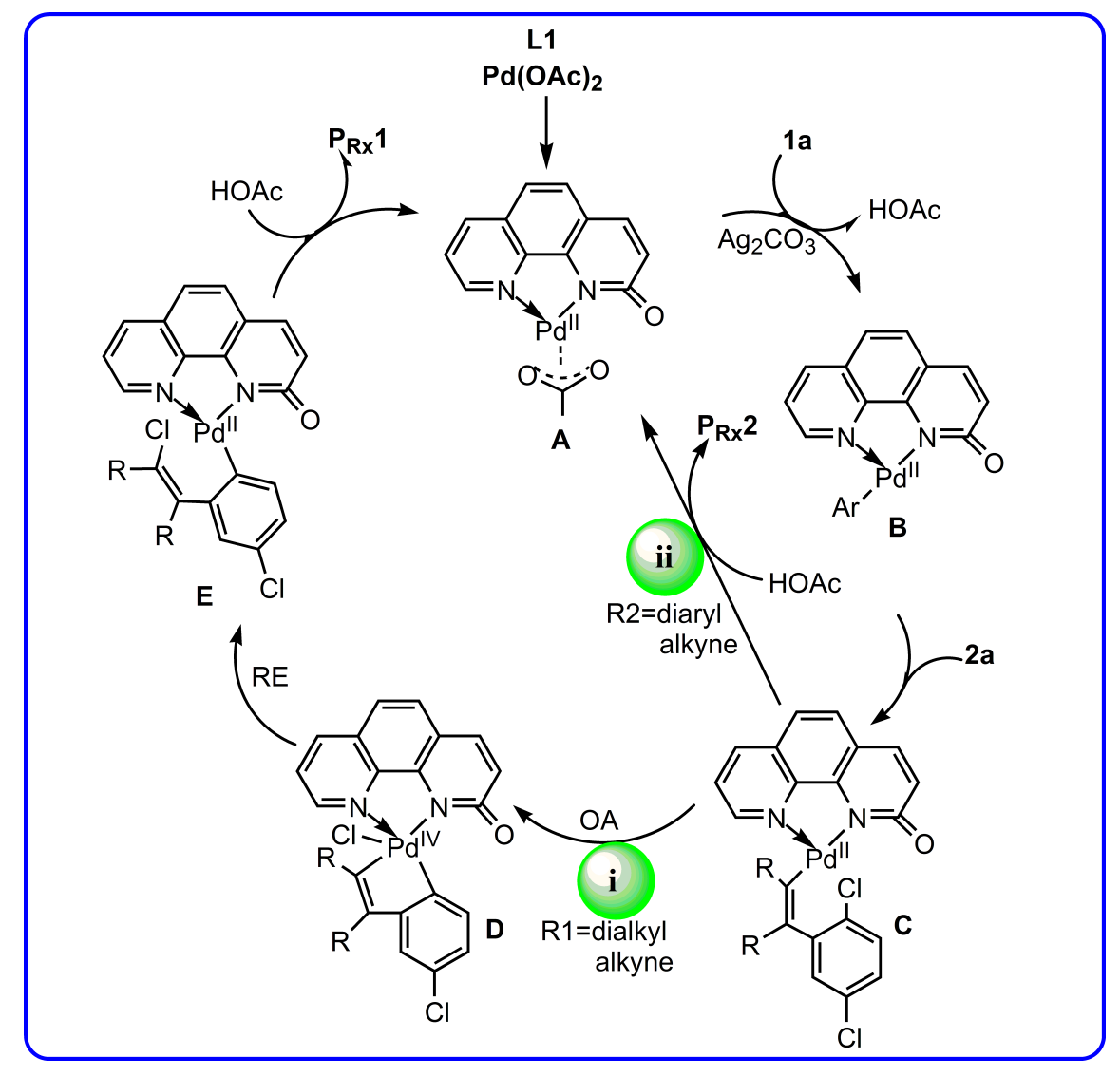

Scheme 3 The proposed catalytic cycle proposed by Duan group ${ }^{10}$.

As the examples of the synthesis of alkenyl chlorides developed from a ligand-promoted palladium-catalyzed $\mathrm{C}-\mathrm{H}$ activation of internal alkynes with simple arenes without directing groups, the reactions reported by Duan's group deserve further study to clarify the detailed mechanism, e.g., the rate-determining and selectivity-determining step(s). In this work, several key issues related to the reaction were solved using density functional theory calculations. (1) what is the origin of chemoselectivity of a $82: 9$ ratio for $\mathbf{P}_{\mathbf{R} 1} \mathbf{1} / \mathbf{P}_{\mathbf{R} 1} \mathbf{2}$ when the alkyne is $\mathbf{2 a} \mathbf{1}$ with $\mathbf{L} \mathbf{1}$ as the ligand? (2) When ligand $\mathbf{L} \mathbf{1}$ is replaced with $\mathbf{L} \mathbf{2}$, why no product ? (3) The substituent effects on chemoselectivity should be rationalized. (4) As previously reported, the bidentate ligand (L2 ) coordinates with palladium acetate to form a square-planar species ${ }^{19}$. Because the bidentate ligand L1 (2-OH-1,10-phenanthroline) differs from L2 only by one $\mathrm{OH}$ group, whether the most stable compound formed by the reaction of $\mathbf{L} \mathbf{1}$ with palladium acetate is the same to the one formed by the coordination of ligandL2 (1,10-phenanthroline) with palladium acetate or not? This work presents a further understanding of palladium-catalyzed $\mathrm{C}-\mathrm{H}$ arylation of alkynes with arenes and provides helpful informatiom for an efficient design of new related reactions.

\section{Computational details}

All of our calculations were conducted with the Gaussian 09 software $^{20}$. The geometry optimization of all the complexes were performed at the M06 level ${ }^{21}$, and the basis set lanL2DZ ${ }^{22}$ was used for $\mathrm{Pd}$ and $\mathrm{Cl}$ and $6-31 \mathrm{~g}(\mathrm{~d})^{23}$ for other atoms. Polarization functions ${ }^{24}$ were added for $\mathrm{Pd}$ with $\zeta_{\mathrm{f}}=1.472$ and $\mathrm{Cl}$ with $\zeta_{\mathrm{d}}=$ 0.640 in the calculation. Frequencies for all reported structures at the same level of theory were analytically computed to confirm all the stationary points as minima (zero imaginary frequency), or transition states (only one imaginary frequency). An intrinsic reaction coordinate (IRC) ${ }^{25}$ analysis was carried out to identify that transition states smoothly connect two relevant minima. To consider the effects of solvent, single-point 
energy calculations for all the species were obtained using a self-consistent reaction field (SCRF) method based on the polarizable continuum model $(\mathrm{PCM}){ }^{26}$ at a higher level of $\mathrm{M} 06 / 6-311++\mathrm{G}\left(\mathrm{d}\right.$, p) (SDD ${ }^{27}$ basis set for $\mathrm{Pd}$ and $\mathrm{Cl}$ atoms), using 1,4-dioxane as solvent corresponding to the experimental conditions. The M06 functional ${ }^{28}$ has been confirmed to provide accurate energy calculations for organic transition metal systems ${ }^{29-34}$. And the natural population analysis (NPA) charge calculations were carried out for selected systems $^{35}$.

\section{Result and discussion}

\subsection{L1 Ligand-Promoted Reaction}

\subsubsection{Relative Stabilities of Various Pd (II) Initial Species}

In the experiments reported by Duan et al., the reaction shown in Scheme 2 (entry 1) does not occur when no ligand is added, implying that ligandL1 is a key factor in the efficient conversion of the catalytic reaction. Thus we investigated the catalytic active species in this system. Firstly, we considered the reaction of the bidentate $\mathrm{N}, \mathrm{N}$ ligandL1 with $\mathrm{Pd}(\mathrm{OAc})_{2}$ to give a compelxL1-I , the calculated results shown in Figure 1. As shown in Figure 1a, there are two similarly potential pathways for the formation of the complex L1-I . One is the monodentate-chelation route (black line), another is the bidentate-chelation channel (green line). It is found that the the formation of the complex L1-I both thermodynamically and kinetically favors the bidentate-chelation pathway with the exothermicity of $-30.2 \mathrm{kcal} / \mathrm{mol}$. Notably, the hydroxyl deprotonation of the two pathways(via TS1'-2' andTS1-2 ) are barrierless processes. In addition, we examined various possible initial $\mathrm{Pd}^{\mathrm{II}}$ species in the reaction system to establish the most stable palladium species. Apart from the catalyst $\mathrm{Pd}(\mathrm{OAc})_{2}$, there also exist some species such as the substrates1,4-dichlorobenzene (1a ) and 4octane (2a1 ), the solvent 1,4-dioxane (S ) and ligand (L1 ). All four species can coordinate with $\mathrm{Pd}(\mathrm{OAc})_{2}$. All of the possible $\mathrm{Pd}(\mathrm{OAc})_{2}$ adducts formed with the four species mentioned above were calculated and shown in Scheme 4. Evidently, the bidentate N, N-coordinated speciesL1-I is found to be the most stable and a square planer geometry. It can be obviously observed that the C1-N1-Pd-O1 lies on the same plane, as indicated by the $\mathrm{D}(\mathrm{C} 1 \mathrm{~N} 1 \mathrm{PdO} 1)=179.1^{\mathrm{O}}$ (see Figure $\left.1 \mathrm{~b}\right)$. In the most stable complex L1-I the resting acetate anion is a bidentate ligand, which is different from the most stable structure formed by the coordination of ligand (L2 ) with palladium acetate ${ }^{19}$. Therefore, the bidentate N, N-coordinated species L1-I was chosen as the active catalyst $\mathbf{K}$ in this work.

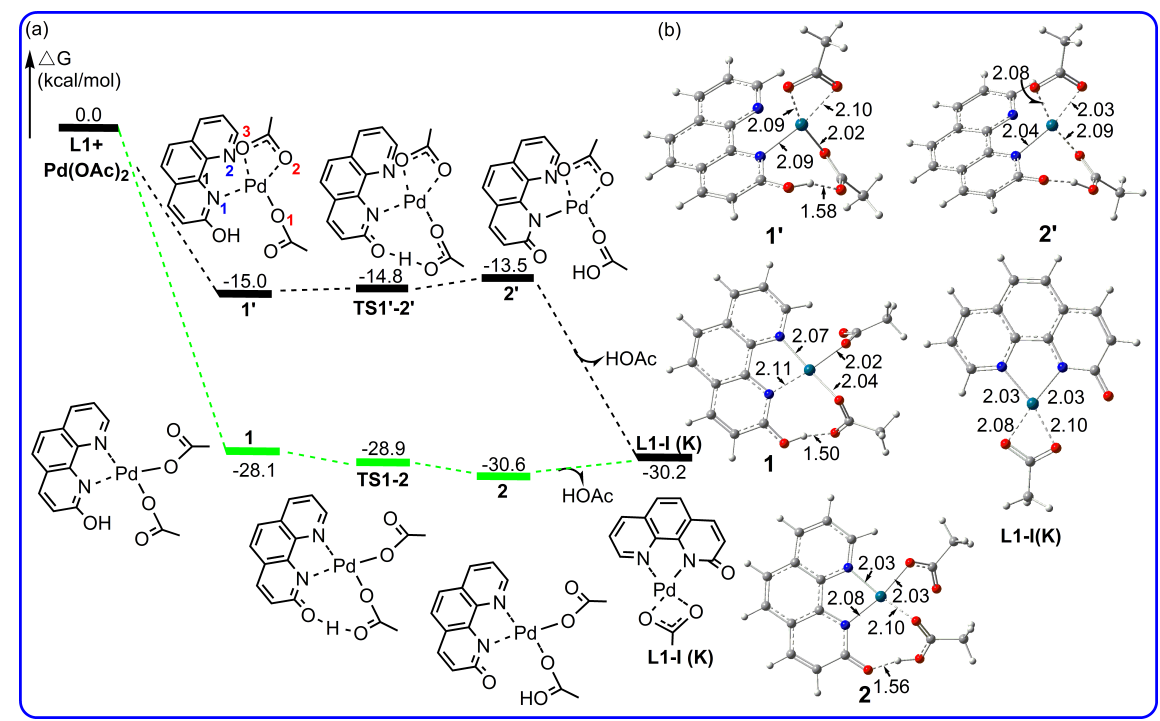

Figure $\mathbf{1}$ The potential energy surface of the formation of the active catalyst $\mathbf{K}$ with $\mathbf{L} \mathbf{1}$ as the ligand. The free energies are given in $\mathrm{kcal} / \mathrm{mol}$. 


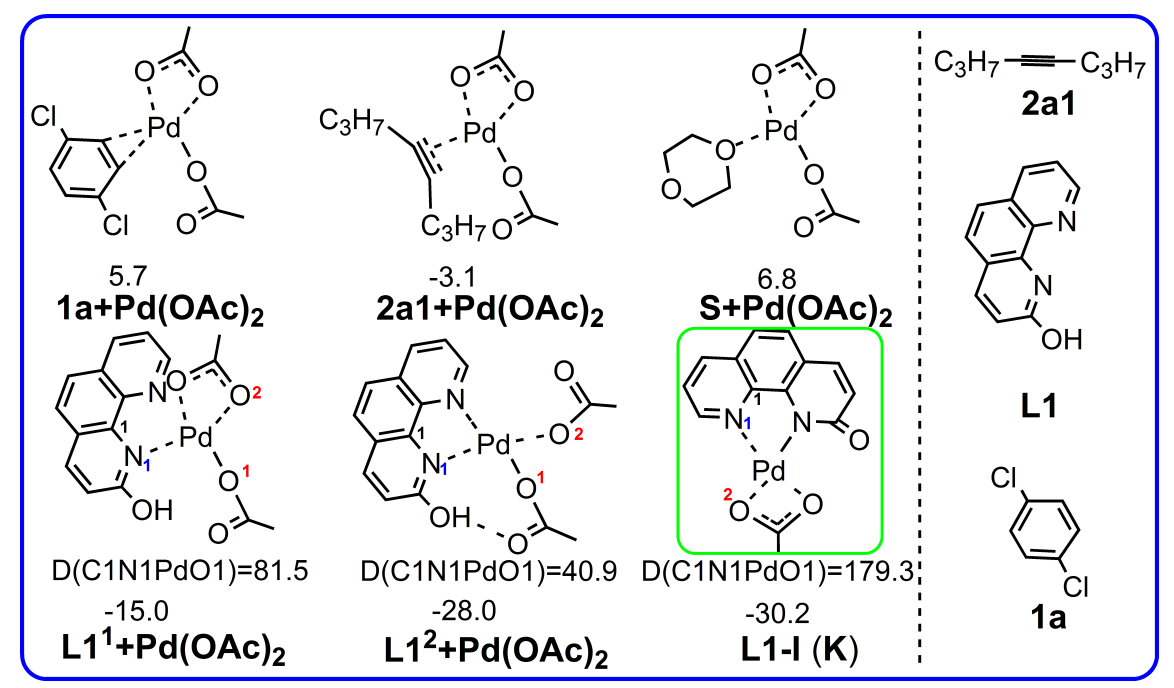

Scheme 4 Some possible Pd (II) initial species. The free energies are given in kcal/mol.

\subsubsection{C $\left(\mathrm{sp}^{2}\right)-\mathrm{H}$ bond Cleavage of Aromatic Ring and Alkyne Insertion}

Consistent with the proposal in Scheme 3, C-H bond cleavage of the 1,4-chlorobenzene was proposed to initiate the reaction in this work, followed by insertion of alkyne. The mechanisms calculated and the optimized key intermediate $\mathbf{7}$ and transition stateTS3-4 together with important structural parameters are presented in Figure 2. After the formation of the active catalystK, the C-Høbond in substrate 1a coordinates with the active catalyst $\mathbf{K}$ to afford a unstable complex $\mathbf{3}$. The coordination process is endothermic by $16.4 \mathrm{kcal} / \mathrm{mol}$. Subsequently, the intermediate $\mathbf{3}$ undergoes the concerted metalation-deprotonation (CMD) process via TS3-4, generating a 16e tetra-coordinate square-planar intermediate $\mathbf{4}$. The barrier calculated is $24.8 \mathrm{kcal} / \mathrm{mol}$, and the exergonicity of this step is $-6.2 \mathrm{kcal} / \mathrm{mol}$. Transition state TS3-4 is also the rate-determining step from the reactant to product. A subsequent dissociation of one HOAc molecule in 4affords a unstable tri-coordinated T-shape intermediate 5 over 4 by $8.1 \mathrm{kcal} / \mathrm{mol}$. As exhibited in Figure 2, the coordination of substrate 4-octyne (2a1) molecule to Pd generates intermediate 6 ready for subsequent alkyne insertion. Then, the alkyne inserts into the $\mathrm{Pd}-\mathrm{C}(\operatorname{aryl})$ bond of $\mathbf{6}$ viaTS6-7 with an energy demand of $21.2 \mathrm{kcal} / \mathrm{mol}$, leading to the formation of alkenyl palladium intermediate $\mathbf{7}$. This process is exothermic by $-7.8 \mathrm{kcal} / \mathrm{mol}$. It is worth noting that in alkenyl palladium intermediate $\mathbf{7}$, the aromatic-ring moiety is coordinated with $\mathrm{Pd}$, and the coordination bond lengths are 2.42 and $2.46 \AA$, respectively. 


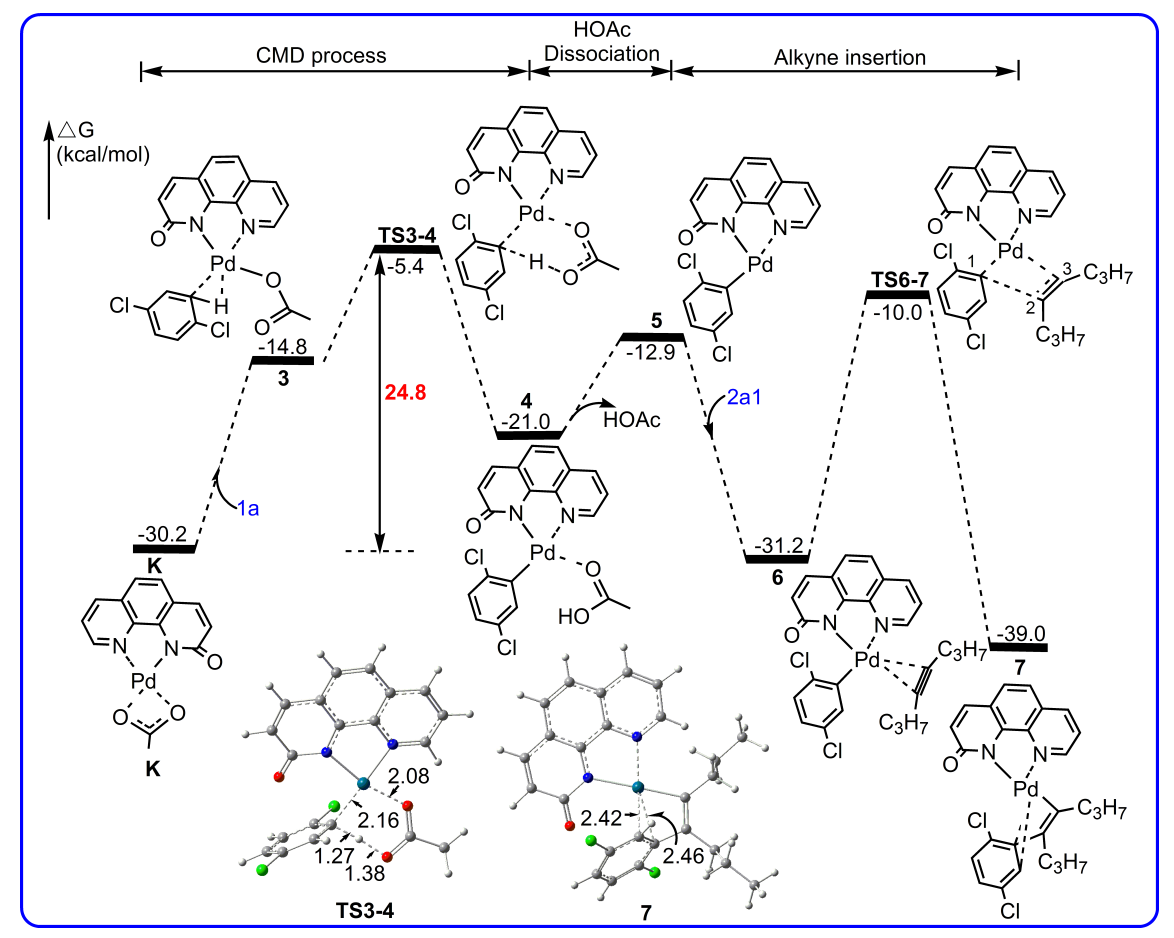

Figure 2 The potential energy surface for $\mathrm{C}\left(\mathrm{sp}^{2}\right)-\mathrm{H}$ cleavage of 1,4-chlorobenzene and alkyne insertion with $\mathbf{L} 1$ as the ligand. The free energies are given in $\mathrm{kcal} / \mathrm{mol}$.

\subsubsection{The Origins of Chemoselectivity of the 82:9 Ratio for $P_{R 1} 1 / P_{R 1} 2$}

As shown in Scheme 2 entry 1, when the $\mathrm{R}$ substituent in alkyne2a is the n-propyl (R1 ) group, the ratio of $\mathbf{P}_{\mathbf{R} 1} \mathbf{1}$ (alkenyl chloride) to $\mathbf{P}_{\mathbf{R} \mathbf{1}} \mathbf{2}$ (trisubstituted olefin) is 82: 9. In this section, we explore the paths that finally end into $\mathbf{P}_{\mathbf{R} \mathbf{1}} \mathbf{1}$ and $\mathbf{P}_{\mathbf{R} \mathbf{1}} \mathbf{2}$ and subsequently disclose the origins of the chemoselectivity. With the alkenyl $\mathrm{Pd}^{\mathrm{II}}$ intermediate $\mathbf{7}$ as the starting point (Figure 3a), there are two potential regiodivergent pathways, leading to $\mathbf{P}_{\mathbf{R} 1} \mathbf{1}$ and $\mathbf{P}_{\mathbf{R} 1} \mathbf{2}$, respectively. Figure 3 a shows the free energy profiles. The right pathways leads to $\mathbf{P}_{\mathbf{R} \mathbf{1}} \mathbf{1}$, and the left pathway generates $\mathbf{P}_{\mathbf{R} \mathbf{1}} \mathbf{2}$. Optimized geometries of key intermediates and transition states involved are exhibited in Figure 3b. Along the right pathway of Figure 3a, a ligand exchange (7-8) is required, in which aromatic ring moiety is replaced by $\mathrm{Cl}$ atom to give the less unstable intermediate $\mathbf{8}$ ready for subsequent 1,4-chlorine migration. In $\mathbf{8}$, the distance of $\mathrm{Pd}$ and $\mathrm{Cl}$ atoms is $2.09 \AA$ (see Figure $3 \mathrm{~b}$ ). Then, oxidative addition with $\mathrm{C}(\operatorname{aryl})-\mathrm{Cl}$ bond cleavage of $\mathbf{8}$ occurs via TS8-9 with an energy demand of $16.0 \mathrm{kcal} / \mathrm{mol}$, giving a five-membered palladacycle $\mathbf{9}$. This step is calculated to surpass an overall barrier of $21.3 \mathrm{kcal} / \mathrm{mol}$ (the difference between TS8-9 and $\mathbf{1 3}$ ), with a slight exergonicity of $-4.6 \mathrm{kcal} / \mathrm{mol}$. From $\mathrm{Pd}(\mathrm{IV})$ species $\mathbf{9}$, the $\mathrm{C}$ (alkenyl)-Cl bond reductive elimination takes place to give the four-coordination intermediate $\mathbf{1 0}$, which is almost isoenergetic with $9(-41.5 \&-42.3 \mathrm{kcal} / \mathrm{mol})$. The barrier calculated in this transformation is $16.2 \mathrm{kcal} / \mathrm{mol}$. In fact, the two successively oxidative addition with cleavage of the $\mathrm{C}(\mathrm{aryl})-\mathrm{Cl}$ bond of $\mathbf{8}$ and reduction elimination by the construction of the Cl-C(alkenyl) bond realizes a formal 1,4-chlorine migration. Next, 10 undergoes ligand substitution to give intermediate 11 with the endoergonicity of $2.3 \mathrm{kcal} / \mathrm{mol}$. Subsequently, protonation occurs with HOAc molecule to obtain product-coordinated adduct $\mathbf{1 2}$. The barrier involved for this step is $15.6 \mathrm{kcal} / \mathrm{mol}$ (TS11-12 -11 ). Finally, the removal of active catalyst $(\mathbf{K})$ from $\mathbf{1 2}$ generates alkenyl chloride product $\left(\mathbf{P}_{\mathbf{R} \mathbf{1}} \mathbf{1}\right)$.

On the other hand, along with the left pathway of Figure 3a ending $\operatorname{in} \mathbf{P}_{\mathbf{R} 1} \mathbf{2}$, the aromatic ring moiety in alkenyl $\mathrm{Pd}^{\mathrm{II}}$ intermediate $\mathbf{7}$ is substituted with carbonyl oxygen of HOAc to form a $16 \mathrm{e}$ intermediate 13 . subsequently, $\mathbf{1 3}$ evolves into product-coordinated adduct14 by undergoing protonation process via 
TS13-14 with a barrier of $23.1 \mathrm{kcal} / \mathrm{mol}$ (TS13-14-13 ). In the final step, the release of the active catalyst (K) from 14 gives trisubstituted olefin product $\left(\mathbf{P}_{\mathbf{R} \mathbf{1}} \mathbf{2}\right)$. Notably, in $\mathbf{1 4}, \mathrm{Pd}$ actually coordinates with the C-H oelectrons of the double bond (Pd-H: $2.04 \AA$; Pd-C: $2.58 \AA$ ) instead of the double bond, which can be attributed to steric repulsion.

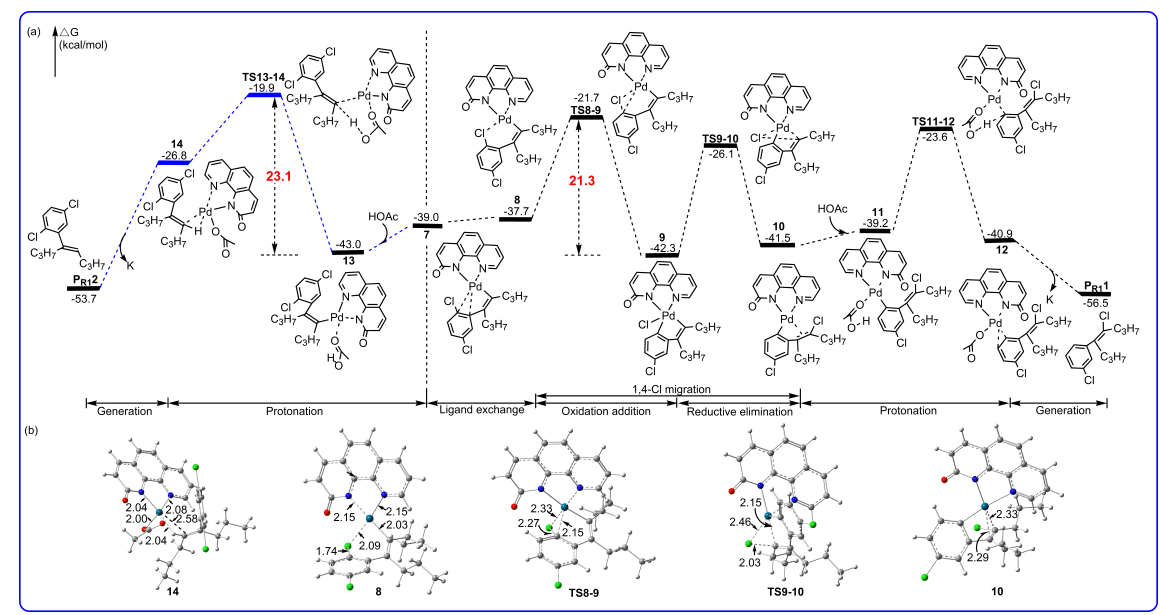

Figure $\mathbf{3}$ The potential energy surface for $\mathrm{Pd}(\mathrm{II})$-catalyzed tranformation from $\mathbf{7}$ to products $\mathbf{P}_{\mathbf{R} \mathbf{1}} \mathbf{1}$ and $\mathbf{P}_{\mathbf{R} 1} \mathbf{2}$ with $\mathbf{L} 1$ as the ligand. The free energies are given in $\mathrm{kcal} / \mathrm{mol}$.

From Figure 3, it can be clearly seen that TS8-9 andTS13-14 are the chemodivergence-determining transition states towards alkenyl chloride product $\left(\mathbf{P}_{\mathbf{R} \mathbf{1}} \mathbf{1}\right)$ and trisubstituted olefin $\left(\mathbf{P}_{\mathbf{R} \mathbf{1}} \mathbf{2}\right)$, respectively. The overall barrier for 13-TS8-9 associated with oxidative addition is lowered by $1.8 \mathrm{kcal} / \mathrm{mol}$ in comparison to 13-TS13-14 related to protonation process, which means that alkenyl chloride $\left(\mathbf{P}_{\mathbf{R 1}} \mathbf{1}\right)$ is the major product. The calculated chemoselectivity is $9.4: 1$ in $298 \mathrm{~K}$. The result is well consistent with the experimentally observed a 82:9 (9.1:1) ratio for the L1ligand-promoted $\mathrm{Pd}^{\mathrm{II}}$-catalyzed $\mathrm{C}-\mathrm{H}$ activation of arene with alkyne (entry 1 in Scheme 2). As seen from Figures 2 and 3, the rate-determining step of the whole catalytic cycle is CMD process via TS3-4 after the formation of active catalyst $\mathbf{K}$. The reaction energy barrier for this step is $24.8 \mathrm{kcal} / \mathrm{mol}$, which is comparable with the observed yield $(81 \%)$ of major product $\mathbf{P}_{\mathbf{R} \mathbf{1}} \mathbf{1}$ under experimental conditions.

\subsection{L2 ligand Promoted Reaction}

Duan et al. found that, using L2 as the ligand (entry 2 in Scheme 2), the reaction did not proceed at all and no product was obtained. To understand this interesting observation, we firstly investigated the relative stabilities of various adducts formed by the coordination of L2 ligand with $\mathrm{Pd}(\mathrm{OAc})_{2}$ shown in Scheme 5, and examined two sequential processes involving $\mathrm{C}\left(\mathrm{sp}^{2}\right)-\mathrm{H}$ bond cleavage of aromatic ring through CMD process and alkyne insertion from the starting materials $\left(\mathbf{L} 2+\mathbf{P d}(\mathbf{O A c})_{2}\right)$ (Figure 4).

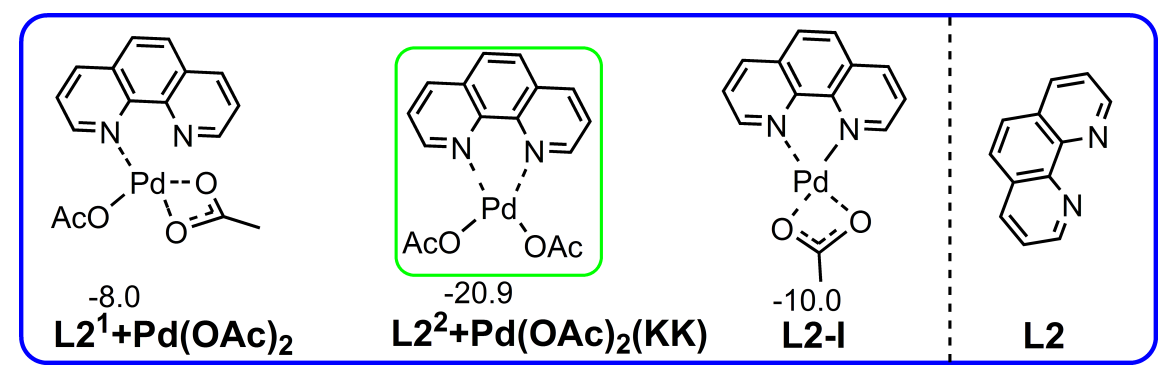


Scheme 5 Some possible Pd (II) initial species with L2as the ligand. The free energies are given in kcal/mol.

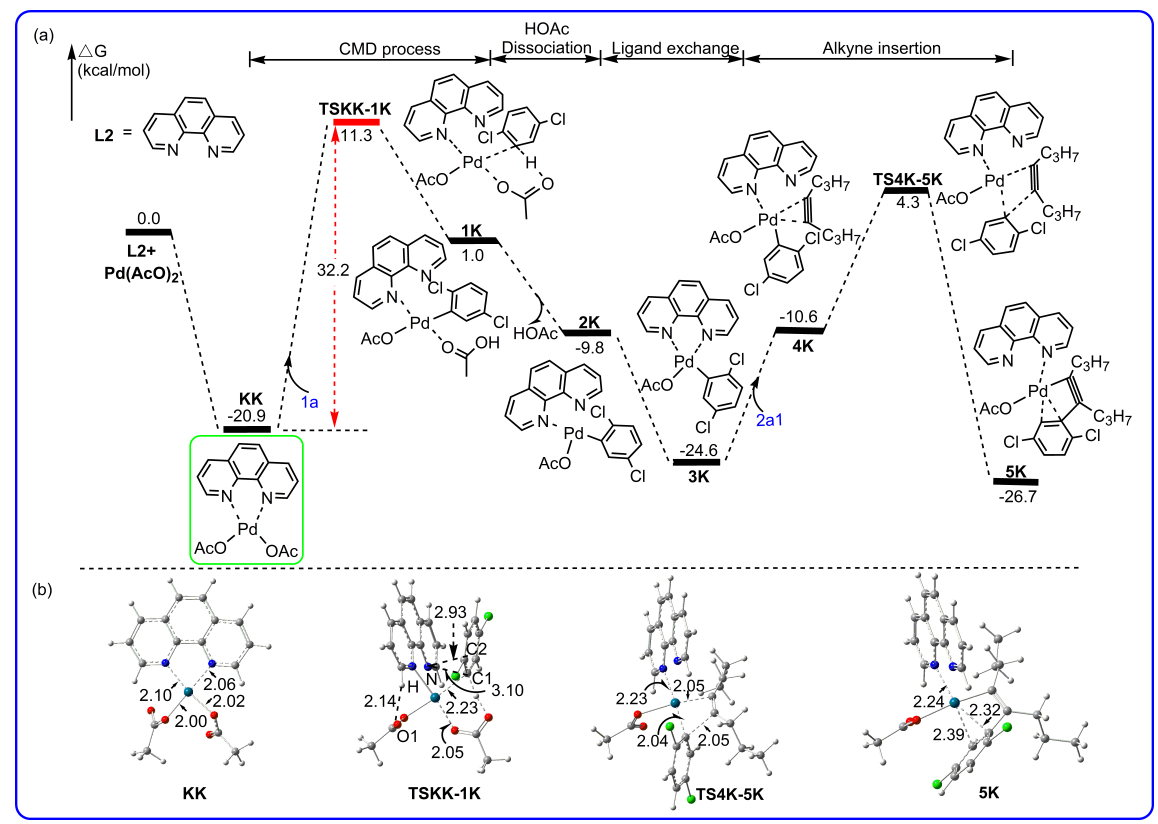

Figure 4 The potential energy surface for $\mathrm{Pd}(\mathrm{II})$-catalyzed $\mathrm{C}\left(\mathrm{sp}^{2}\right)-\mathrm{H}$ bond cleavage of 1,4-chlorobenzene and alkyne insertion with $\mathbf{L} 2$ as the ligand. The free energies are given in $\mathrm{kcal} / \mathrm{mol}$.

As shown in Scheme 5, it is found that the bidentate N, N-coordinated species $\mathbf{L 2}^{\mathbf{2}}+\mathbf{P d}(\mathbf{O A c})_{\mathbf{2}}(-20.9$ $\mathrm{kcal} / \mathrm{mol})$ is the most stable than the other two complexes $\left(\mathbf{L 2}^{\mathbf{2}}+\mathbf{P d}(\mathbf{O A c})_{\mathbf{2}}\right.$ and $\left.\mathbf{L 2}-\mathbf{I}\right)$, and it is used as the active catalyst (KK) in this work. In four-coordinated square-planer species $\mathbf{K K}$, the bidentate nitrogennitrogen ligand coordinates with $\mathrm{Pd}$ and oxygen atoms of two acetate anion form two covalent bonds with $\mathrm{Pd}$, respectively, which is consistent with the structure reported by the literature ${ }^{19}$. In the following step, the $\mathrm{Pd}$ inKK cleaves a Pd-N coordination bond followed by undergoing CMD process together with the substrate 1a . The CMD process is $21.9 \mathrm{kcal} / \mathrm{mol}$ endothermic via TSKK-1K by overcoming a free energy barrier of 32.2 $\mathrm{kcal} / \mathrm{mol}$, indicating that CMD process is both thermodynamically and kinetically unfavorable and difficult to proceed. This fact explains why there is no reaction under experimental conditions with $\mathbf{L} \mathbf{2}$ as the ligand, as the documents recorded that 1,10-phenanthroline(1,10-phen) are seldom used for the palladium-catalysed C-H activation reactions. ${ }^{13 b-c}$ Note that the calculated barrier of the CMD process forKK $\mathbf{- 1 K}$ with $\mathbf{L 2}$ as the ligand is $32.2 \mathrm{kcal} \mathrm{mol}^{-1}$, much higher than that for $\mathbf{3} \mathbf{- 4}\left(24.8 \mathrm{kcal} \mathrm{mol}^{-1}\right)$ with $\mathbf{L} \mathbf{1}$ as the ligand in Figure 2. The instability of TS1K-KK $(11.3 \mathrm{kcal} / \mathrm{mol})$ compared with TS3-4 $(-5.4 \mathrm{kcal} / \mathrm{mol})$ can be attributed to greater steric repulsion, instead of low coordinate ability without strong chelating groups as proposed by Duan et al ${ }^{13 c}$. This is indicated by the $\mathrm{O} 1 \ldots \mathrm{H}, \mathrm{N} \ldots \mathrm{C} 1$, and N...C2 interaction at $2.14 \AA$, $2.93 \AA$, and $3.10 \AA$ in TSKK , respectively, which are less than the sums of their van der Waals radii $(\mathrm{N}, 1.55 \AA$; $\mathrm{C}$, $1.70 \AA ; \mathrm{O}, 1.52 \AA ; \mathrm{H}, 1.20 \AA$ ). In the following step, intermediates $\mathbf{1 K}$ successively undergo HOAc dissociation and ligand exchange to form the $16 \mathrm{e} \mathbf{3 K}$, as shown in Figure 4a, the coordination of $\mathbf{2 a 1}$ molecule to $\mathrm{Pd}$ generates intermediate $\mathbf{4 K}$ ready for subsequent alkyne insertion. The calculated barrier for alkyne insertion via TS4K-5K is $28.9 \mathrm{kcal} / \mathrm{mol}(\mathbf{3 K}-\mathbf{T S} 4 \mathbf{K}-\mathbf{5 K})$, higher than the overall barrier of the process via TS3-4 $(24.8 \mathrm{kcal} / \mathrm{mol})$ in Figure 2. Clearly, the energy barrier is still higher and the reaction is difficult to occur.

Although the bidentate ligand L1 (2-OH-1,10-phenanthroline) developed by Duan's group differs from L2 by one $\mathrm{OH}$ group, lack of $\mathrm{OH}$ group in $\mathbf{L} 2$ ligand results in the greater steric repulsion in CMD process. As a result, the reactivity is deceased to no product obtained.

\subsection{Substituent Effects on Chemoselectivity}


Interestingly, the reaction affords hydroarylation product $\mathbf{P}_{\mathbf{R} \mathbf{2}} \mathbf{2}$ with a yield of $91 \%$ when the n-propyl (R1 ) group in alkyne (2a1 ) is replaced with the 3,5-dimethylphenyl (R2 ) group (2a2), which is contrary to the case discussed above. This obvious substituent effects on chemoselectivity urged us to explore the origins. It is found that the reaction with a diarylalkyne $(\mathbf{2 a 2})$ as the substrate follows a mechanism similar to that discussed above for the reaction with a dialkylalkyne (2a1 ) as substrate.

For simplicity's sake, the following discussion only deals with the results starting from $\mathbf{5}$. Figure 5 summarizes calculated results for the insertion of diarylalkyne $(\mathbf{2 a 2})$. The T-shape intermediate $\mathbf{5}$ first coordinates with the diarylalkyne $(\mathbf{2 a 2})$ molecule to form the intermediate $\mathbf{6}_{\mathrm{Ar}}$ ready for subsequent alkyne insertion. This step is exothermic by $-14.0 \mathrm{kcal} / \mathrm{mol}$. Then, the alkyne inserts into the $\mathrm{Pd}-\mathrm{C}(\operatorname{aryl})$ bond of $\mathbf{6}_{\mathrm{Ar}}$ via TS6 $\mathbf{A r}_{\mathbf{A r}}-\mathbf{7}_{\mathrm{Ar}}$ with an overall barrier of $21.6 \mathrm{kcal} / \mathrm{mol}\left(\mathbf{K}-\mathbf{T S} \mathbf{6}_{\mathrm{Ar}}-\mathbf{7}_{\mathbf{A r}}\right)$, leading to the formation of alkenyl palladium intermediate $\mathbf{7}_{\mathbf{A r}}$. In comparison with TS6-7 in Figure 2, it is found that the free energy of $\mathbf{T S} \mathbf{6}_{\mathbf{A r}} \mathbf{~}^{-}$ $\mathbf{7}_{\mathbf{A r}}$ is $1.4 \mathrm{kcal} / \mathrm{mol}$ higher than that of TS6-7, which can be analyzed by their NBO charge. As shown in Figure 6, the NBO charge at $\mathrm{Pd}(0.403 \mathrm{e})$ in $\mathbf{T S 6} \mathbf{A r}_{\mathbf{A r}} \mathbf{-} \mathbf{A r}_{\mathbf{A r}}$ is more positive than that at $\mathrm{Pd}(0.392 \mathrm{e})$ in TS6-7 , and the NBO charge at C1 (-0.133e) atom in $\mathbf{T S 6} \mathbf{A r}_{\mathbf{A r}}-\mathbf{7}_{\mathbf{A r}}$ more negative than that at $\mathrm{C} 1(-0.128 \mathrm{e})$ in TS6-7 . Evidently, the electrostatic interaction between $\mathrm{Pd}$ and $\mathrm{C} 1$ atoms in $\mathbf{T S} \mathbf{6}_{\mathbf{A r}} \mathbf{-} \mathbf{7}_{\mathbf{A r}}$ is the stronger than that in TS6-7. The stronger the Pd-C1 bond, the higher the transition state energy. Moreover, because of the steric effects, the structure $\mathbf{T S} \mathbf{6}_{\mathbf{A r}} \mathbf{-} \mathbf{7}_{\mathbf{A r}}$ is not more stable than $\mathbf{T S 6 - 7}$, which can be manifested by the shorter C1-C2 and Pd-C3 bond distances in TS6 $\mathbf{A r}_{\mathbf{A r}}-\mathbf{7}_{\mathbf{A r}}$ (2.03 and $2.06 \mathrm{~A}$, respectively) compared with the corresponding values in TS6-7(2.07 and $2.08 \mathrm{~A}$, respectively).

Thus, the reasons that $\mathbf{T S} \mathbf{6}_{\mathbf{A r}} \mathbf{-} \mathbf{7}_{\mathbf{A r}}$ in energy is higher than $\mathbf{T S 6 - 7}$ can be attributed to the stronger electrostatic attraction between $\mathrm{Pd}$ and $\mathrm{C} 1$ atoms and the stronger steric effects between $\mathrm{C} 1-\mathrm{C} 2$ and $\mathrm{Pd}-\mathrm{C} 3$ bonds in

$\mathrm{TS6}_{\mathrm{Ar}}-7_{\text {Ar. }}$.

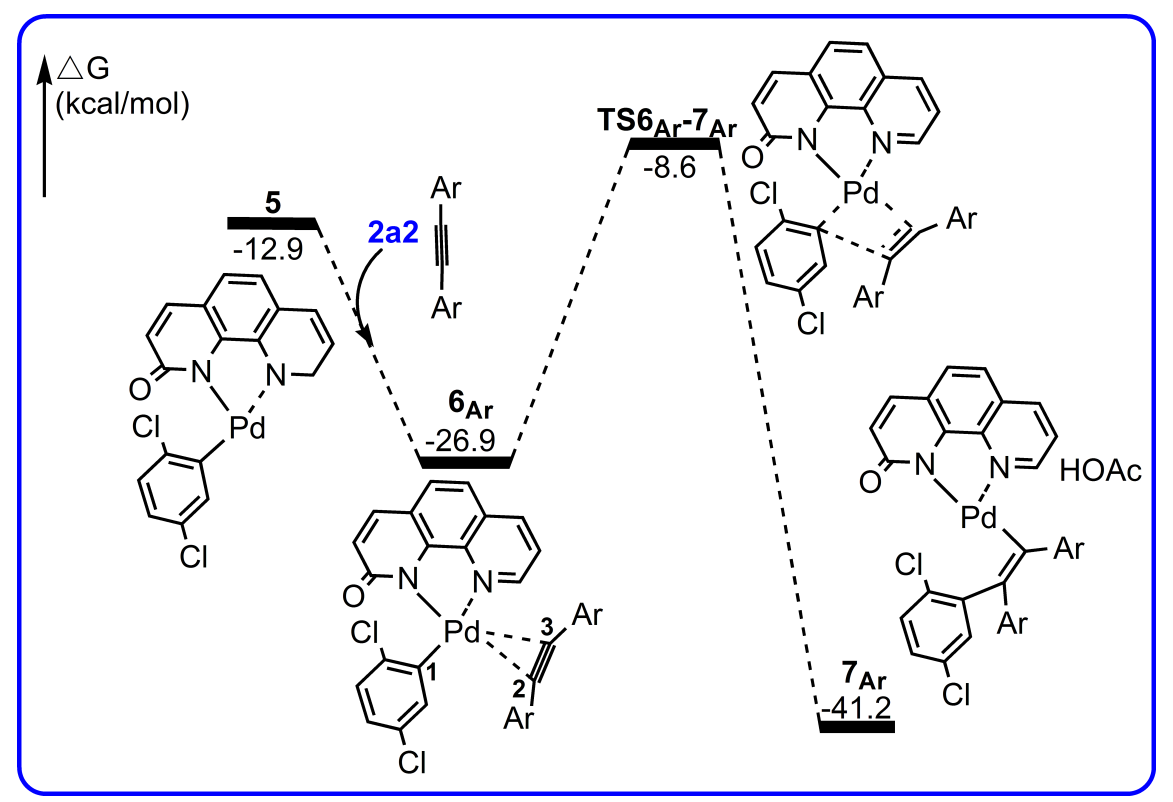

Figure $\mathbf{5}$ The potential energy surface for Pd(II)-catalyzed alkyne insertion with the diarylalkyne $\mathbf{2 a 2}$. The free energies are given in $\mathrm{kcal} / \mathrm{mol}$. 


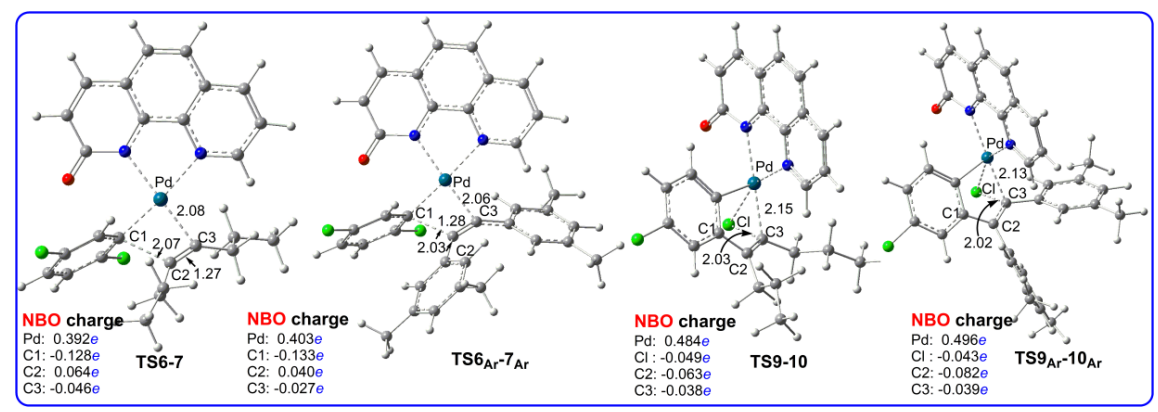

Figure 6 The NBO charge of transition states TS6-7 ,TS6 $\mathbf{A r}_{\mathbf{A r}}-\mathbf{7}_{\mathrm{Ar}}, \mathbf{T S 9 - 1 0}$ and $\mathrm{TS9}_{\mathrm{Ar}}-10_{\mathrm{Ar}}$.

Our attention now focuses on the chemoselectivity formation of alkenyl chloride $\mathbf{P}_{\mathbf{R} \mathbf{2}} \mathbf{1}$ and hydroarylation product $\mathbf{P}_{\mathbf{R} \mathbf{2}} \mathbf{2}$. Figure 7 summarizes the calculated results for the transformation of $\mathbf{7}_{\mathbf{A r}}$ to $\mathbf{P}_{\mathbf{R} \mathbf{2}} \mathbf{1}$ and $\mathbf{P}_{\mathbf{R 2}} \mathbf{2}$ - As exhibited by Figure 7, it is not difficult to find that transition state $\mathbf{T S} \mathbf{9}_{\mathbf{A r}} \mathbf{- 1 0}_{\mathbf{A r}}(-11.4 \mathrm{kcal} / \mathrm{mol})$ associated with reductive elimination is the highest point in the channel towards alkenyl chloride $\mathbf{P}_{\mathbf{R} \mathbf{2}} \mathbf{1}$, with the overall barrier of $30.8 \mathrm{kcal} / \mathrm{mol}\left(\mathbf{1 3}_{\mathbf{A r}}-\mathbf{T S} \mathbf{9}_{\mathbf{A r}}-\mathbf{1 0}_{\mathbf{A r}}\right)$. For the formation pathway of the hydrogenation $\mathbf{P}_{\mathbf{R 2}} \mathbf{2}$, the highest point is $\mathbf{T S 1 3} \mathbf{A r}_{\mathbf{A r}}-\mathbf{1 4}_{\mathbf{A r}}(-16.0 \mathrm{kcal} / \mathrm{mol})$ related to protonation process, and the overall barrier of this channel is $26.2 \mathrm{kcal} / \mathrm{mol}\left(\mathbf{1 3}_{\mathbf{A r}}-\mathbf{T S} \mathbf{1 3} \mathbf{A r}_{\mathbf{A r}} \mathbf{- 1 4} \mathbf{A r}\right)$. It should be noted that, from $\mathbf{7}_{\mathbf{A r}}$ , the reaction may almost exclusively proceed viaTS13 $\mathbf{A r}-\mathbf{1} \mathbf{4}_{\mathbf{A}}$, to give trisubstituted olefin $\mathbf{P}_{\mathbf{R 2}} \mathbf{2}$ due to the large barrier difference $(4.6 \mathrm{kcal} / \mathrm{mol})$ between $\mathbf{T S 9} \mathbf{A r}_{\mathbf{A r}} \mathbf{- 1 0} \mathbf{A r}_{\mathbf{A r}}$ andTS13 $\mathbf{A r} \mathbf{- 1 4} \mathbf{A}$. This result is line with the experimental phenomenon $\left(\mathbf{P}_{\mathbf{R 2}} \mathbf{2}\right.$ yield is as high as $\left.91 \%\right)$. The main reason lies in the substituent effects, namely, replacing alkyl group by aryl group results in a electron density decrease of alkynyl carbon to faciliates $\mathrm{C}($ alkynyl)-H activation and makes protonation process easier.

Compare Figures 3 with 7, it can be seen that their obviously differences are the highest points in the two pathways towards alkenyl chloride products $\mathbf{P}_{\mathbf{R} \mathbf{1}} \mathbf{1}$ and $\mathbf{P}_{\mathbf{R} \mathbf{2}} \mathbf{1}$. The highest point in Figure 3 is transition state TS8-9 related to oxidation addition, and the one in Figure 7 is $\mathbf{T S} \mathbf{9}_{\mathbf{A r}} \mathbf{- 1 0} \mathbf{A r}_{\mathbf{A r}}$ associated with reduction elimination. Furthermore, the most obvious points of energy change in the two pathways are the transition stateTS9-10 $(-26.1 \mathrm{kcal} / \mathrm{mol})$ and $\mathbf{T S} \mathbf{A r}_{\mathbf{A r}}-\mathbf{1 0}_{\mathbf{A r}}(-11.4 \mathrm{kcal} / \mathrm{mol})$. In the subsection, to explore the origin of the energy difference of $14.7 \mathrm{kcal} / \mathrm{mol}$, we carried out natural bond orbital (NBO) calculations for the transition states (see Figure 6). The charges at the $\mathrm{Pd}, \mathrm{C} 3$ and $\mathrm{Cl}$ atoms in $\mathbf{T S} \mathbf{9}_{\mathbf{A r}} \mathbf{- 1 0} \mathbf{A r}$ are $0.496 \mathrm{e},-0.039 \mathrm{e}$ and $-0.043 \mathrm{e}$, respectively, and the corresponding values inTS9-10 are $0.484 \mathrm{e},-0.038 \mathrm{e}$ and $-0.049 \mathrm{e}$. It is not difficult to find that the electrostatic attraction between $\mathrm{Pd} \& \mathrm{C} 3$ and $\mathrm{Pd} \& \mathrm{Cl}$ atoms in $\mathbf{T S} \mathbf{9}_{\mathbf{A r}} \mathbf{- 1 0} \mathbf{A r}_{\mathbf{A r}}$ is stronger than those in TS9-10. The stronger electrostatic attractions makes it difficult to break the Pd-C3 and $\mathrm{Pd}-\mathrm{Cl}$ bonds. Moreover, the repulsive force between $\mathrm{C} 2$ and $\mathrm{Cl}$ atoms in

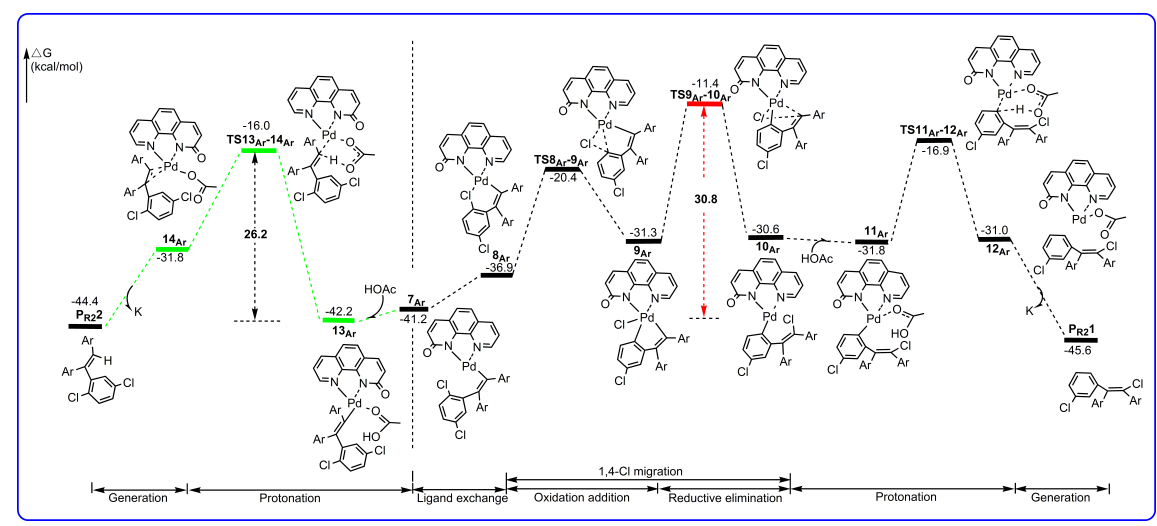


Figure $\mathbf{7}$ The potential energy surface for $\mathrm{Pd}(\mathrm{II})$-catalyzed tranformation from $\mathbf{7}_{\mathbf{A r}}$ to products $\mathbf{P}_{\mathbf{R} \mathbf{2}} \mathbf{1}$ and $\mathbf{P}_{\mathbf{R 2}} \mathbf{2}$ with diarylalkyne $\mathbf{2 a} \mathbf{2}$ substrate. The free energies are given in $\mathrm{kcal} / \mathrm{mol}$.

TS9 $_{\mathbf{A r}} \mathbf{- 1 0} \mathbf{A r}_{\mathbf{A r}}$ is stronger than that in TS9-10, as indicated by calculated NBO charge: $-0.082 \mathrm{e} \&-0.043 \mathrm{e}$ in TS9 $_{\mathbf{A r}}-\mathbf{1 0}_{\mathbf{A r}}$ and $-0.063 \mathrm{e} \&-0.049 \mathrm{e}$ in TS9-10 for $\mathrm{C} 2$ and $\mathrm{Cl}$, respectively. In addition, the higher unstability of TS9 $\mathbf{A r}_{\mathbf{r}}-\mathbf{1 0}_{\mathrm{Ar}}$ can be attributed to the stronger electrostatic attractions between $\mathrm{Pd} \& \mathrm{C} 3$ and $\mathrm{Pd} \& \mathrm{Cl}$, and the stronger repulsive force of $\mathrm{C} 2-\mathrm{Cl}$ bond in comparison toTS9-10 .

In general, when the substituent in substrate $\mathbf{2 a}$ is the n-propyl (R1 ) group, the major product obtained is alkenyl chloride $\mathbf{P}_{\mathbf{R} \mathbf{1}} \mathbf{1}$, and the rate-determining step of the catalytic reaction is CMD process. The origins of chemoselectivity of the 82:9 ratio of $\mathbf{P}_{\mathbf{R} \mathbf{1}} \mathbf{1}$ to $\mathbf{P}_{\mathbf{R} \mathbf{1}} \mathbf{2}$ are related to oxidative addition with $\mathrm{C}($ aryl)-Cl bond cleavage of $\mathbf{8}$ and protonation process viaTS13-14. While the substituent is the 3,5-dimethylphenyl (R2) group, the hydroarylation $\mathbf{P}_{\mathbf{R 2}} \mathbf{2}$ is the major product. At this time, the key step of the whole catalytic cycle is protonation process $\left(\mathbf{1 3}_{\mathrm{Ar}}-\mathbf{T S 1 3} \mathbf{A r}_{\mathbf{r}}-\mathbf{1 4}_{\mathrm{Ar}}\right)$. Three factors, stronger electrostatic attractions between $\mathrm{Pd}$ \&C3 and $\mathrm{Pd} \& \mathrm{Cl}$, repulsive force between $\mathrm{C} 2$ and $\mathrm{Cl}$ atom and aryl substituent effects, are responsible for the reverse chemoselectivity .

\section{Conclusion}

We investigated the detailed mechanism and chemoselectivity in the ligand-promoted $\mathrm{Pd}^{\mathrm{II}}$-catalyzed $\mathrm{C}-\mathrm{H}$ alkeylation of internal alkynes with simple arenes without directing group using DFT calculation. The calculated results revealed that the substituents $(\mathrm{R})$ in alkyne $\mathbf{2 a}$ effect on the mechanism and the chemoselectivity: when $\mathrm{R}$ is n-propyl (alkyl) group, the major product is alkenyl chloride and the rate-determining step of the catalytic reaction is the concerted metalation-deprotonation (CMD) process. The origins of chemoselectivity are related to oxidative addition with the $\mathrm{C}-\mathrm{Cl}$ bond cleavage and protonation process. While $\mathrm{R}$ is 3,5-dimethylphenyl (aryl) group, the reaction almost exclusively afford the corresponding trisubstituted olefins and the key step of the reaction is protonation process. Reductive elimination relative to protonation process is responsible for the large barrier difference. The electrostatic attractions between $\mathrm{Pd} \& \mathrm{C} 3$ and $\mathrm{Pd} \& \mathrm{Cl}$, repulsive force between $\mathrm{C} 2$ and $\mathrm{Cl}$ atom and a electron density decrease of alkynyl carbon caused by the aryl substituent result in reverse chemoselectivity. Bidentate ligand $\mathbf{L} 1$ (2-OH-1,10-phenanthroline) reacts with $\mathrm{Pd}(\mathrm{OAc})_{2}$ to form a most stable square-planer species bearing only one bidentate acetate anion on the palladium atom, which is different from the structure formed by the coordiantion of ligand $\mathbf{L 2}$ (1,10-phenanthroline) with palladium acetate. The $\mathrm{OH}$ group of ligand is crucial to the $\mathrm{C}\left(\mathrm{sp}^{2}\right)$ - $\mathrm{H}$ bond cleavage of aromatic ring through CMD process. Theoretical results provide valuable information for a better understanding of the ligand effects and substituent-controlled chemoselectivity in Pd-catalyzed C-H arylation of alkynes with simple arenes to furnish trisubstituted alkenes or vinyl chlorides through a 1,4-chlorine migration.

\section{References}

1 V. P. Boyarskiy, D. S. Ryabukhin, N. A. Bokach and A. V. Vasilyev,Chem. Rev., 2016 , $116,5894$.

2 Y. Yamamoto, Chem. Soc. Rev., 2014, 43, 1575.

3 L. Ackermann, Acc. Chem. Res., 2014, 47, 281.

4 R. Rossi, F. Bellina and M Lessi, Synthesis, 2010 ,2010 , 4131.

5 P. de Mendoza and A. M. Echavarren, Pure Appl. Chem.,2010 , 82 , 801.

6 T. Kitamura, Eur. J. Org. Chem., 2009 , 2009 , 1111.

7 A. V. Vasil'ev, Russ. J. Org. Chem., 2009 , 45, 1.

8 H. C. Shen, Tetrahedron, 2008, 64, 3885.

9 V. Ritleng, C. Sirlin and M. Pfeffer,Chem. Rev., 2002 ,102, 1731.

10 Z. Li and W. -L. Duan, Angew. Chem. Int. Ed., 2018 ,130,16273. 
11 a) J. Yamaguchi, A. D.Yamaguchi and K. Itami, Angew. Chem. Int. Ed., 2012, 124, 9092-9142; Angew. Chem. Int. Ed., 2012 , 51 , 8960; b)J. Wencel-Delord and F. Glorius, Nature Chem., 2013 , 5 , 369.

12 a)M. Nagamoto, J. -i. Fukuda, M. Hatano, H. Yorimitsu and T. Nishimura, Org. Lett. 2017 , 19 , 5952; b) J. Zhang, R. Shrestha, J. F. Hartwig and P. Zhao, Nature Chem.2016 , 8, 1144; c) A. Biafora, B. A. Khan, J. Bahri, J. M. Hewer and L. J. Goossen, Org. Lett. 2017 , 19 , 1232.

13 a) D. J. Berrisford, C. Bolm and K. B. Sharpless, Angew. Chem., Int. Ed. Engl., 1995, 34 ,1059; b) C. -H. Ying, S. -B. Yan and W. -L. Duan, Org. Lett., 2014, 16 , 2, 500; c) B. Liu, Y. Huang, J. Lan, F. Song and J. You, Chem. Sci.,2013, 4, 2163.

14 a) L. Chu, X. -C. Wang, C. E. Moore, A. L.Rheingold and J. -Q. Yu,J. Am. Chem. Soc., 2013 , 135 , 16344; b) P. S. Thuy-Boun, G. Villa, D. Dang, P. Richardson, S. Su and J. -Q. Yu,J. Am. Chem. Soc., $2013,135,17508 ;$ c) A. N. Campbell, P. B. White, I. A. Guzei and S. S. Stahl, J. Am. Chem. Soc., 2010 , 132, 15116; d) A. N. Campbell, E. B. Meyer and S. S. Stahl, Chem. Commun., 2011 , 47, 10257.

15 a) M. H. Emmert, A. K. Cook, Y. J. Xie and M. S. Sanford,Angew. Chem., Int. Ed., 2011 , 50 , 9409; b) A. Kubota, M. H. Emmert and M S. Sanford, Org. Lett. 2012 ,14, 1760.

16 a) B. Liu, Y. Huang, J. Lan, F. Song and J. You, Chem. Sci.2013 , 4, 2163; b) U. Sharma, T. Naveen, A. Maji, S. Manna and D. Maiti, Angew. Chem. Int. Ed., 2013 ,52, 12669.

17 F. Dai, Q. Gui, J. Liu, Z. Yang, X. Chen, R. Guo and Z. Tan,Chem. Commun. 2013 , 49 , 4634.

18 A. Togni and L. M. Venanzi, Angew. Chem., Int. Ed. Engl.,1994, 33 , 497.

19 F. Ragaini, M. Gasperini, S. Cenini, L. Arnera, A. Caselli, P. Macchi and N. Casati, Chem. Eur. J., 2009, 15,8064 .

20 M. J. Frisch, G. W. Trucks, H. B. Schlegel, G. E. Scuseria, M. A. Robb, et al. Gaussian 09, Revision A.02, Gaussian, Inc., Wallingford CT,2009 .

21 a) Y. Zhao, N. E. Schultz and D. G. Truhlar, J. Chem. Phys.,2005, 123 , 161103; b) Y. Zhao and D. G. Truhlar,Acc. Chem. Res., 2008, 41, 157; c)Y. Zhao and D. G. Truhlar, Theor. Chem. Acc. 2008, 120, 215-241; d) Y. Zhao and D. G. Truhlar, J. Chem. Theory Comput.2009 , 5 , 324.

22 a) P. J. Hay and W. R. Wadt, J. Chem. Phys. 1985 ,82, 299; b) W. R. Wadt and P. J. Hay, J. Chem. Phys.,1985, 82, 284.

23 P. C. Hariharan and J. A. Pople, Theor. Chim. Acta.,1973, 28 , 213.

24 A. W. Ehlers, M. Bohme, S. Dapprich, A. Gobbi, A. Hollwarth, V. Jonas, K. F.

Kohler, R. Stegmann, A. Veldkamp and G. Frenking, Chem.Phys. Lett., 1993, 208, 111.

25 a) K. Fukui, J. Phys. Chem., 1970, 74, 4161-4163; b) K. Fukui, Acc. Chem. Res., 1981 ,14, 363.

26 a) V. Barone and M. Cossi, J. Phys. Chem. A, 1998 ,102 , 1995; b) M. Cossi, N. Rega, G. Scalmani and V. Barone,J. Comput. Chem., 2003 , 24, 669; c) J. Tomasi, B. Mennucci and R. Cammi, Chem. Rev. 2005, 105,2999 .

27 a) P. Fuentealba, H. Preuss, H. Stoll and L. Vonszentpaly,Chem. Phys. Lett., 1982, 89 , 418-422; b) L. V. Szentpaly, P. Fuentealba, H. Preuss and H. Stoll, Chem. Phys. Lett., 1982, 93, 555; c) P. Fuentealba, H. Stoll, L. V. Szentpaly, P. Schwerdtfeger and H. Preuss, J. Phys. B: At. Mol. Phys., 1983, 16 , L323.

28 S. Grimme, J. Comput. Chem., 2006 , 27 , 1787.

29 G. Tran, K. D. Hesp, V. Mascitti and J A. Ellman, Angew. Chem. Int. Ed., 2017 , 56 , 5899.

30 Y. -Y. Jiang, Z. Li and J. J. Shi, Organometallics,2012, $31,4356$.

31 Z. Yang, H. Yu and Y. Fu, Chem. Eur. J., 2013 ,19 , 12093. 
32 G. Huang and P. Liu, ACS Catal., 2016 , 6 , 809.

33 L. Xu, L. Chung and Y. -D.Wu, ACS Catal., 2016 ,6 , 483.

34 J. L. Yu, S. Q. Zhang and X. Hong, J. Am. Chem. Soc., 2017, 139, 7224.

35 E. D. Glendening, A. E. Read, J. E. Carpenter and F. Weinhold, NBO, version 3.1; Gaussian, Inc., Pittsburgh, PA, 2003. 